\title{
Viral hepatitis and interstitial lung diseases: can HRCT assess their relation and characterize its pattern?
}

\author{
Ahmed Samir $^{* *}$, Ahmed Adel El-Beheiry ${ }^{1}$ (D) Heba Said Gharraf ${ }^{2}$ (I) and Mohamed Hossameldin Khalifa ${ }^{1}$ (D)
}

\begin{abstract}
Background: Clinical and pathological studies suggested the presence of a relation between active viral hepatitis and interstitial lung diseases (ILD) ranging from mild to moderate relation. Most studies attribute this relation to viral geno-physiological characteristics. The purpose of the study is first to assess the role of high-resolution computed tomography (HRCT) in evaluating the relation between viral hepatitis and ILDs, then to characterize the predominant pattern of ILD that affects patient management and prognosis.

Results: This prospective study was conducted on 300 patients with viral hepatitis. They were divided into three groups of patients according to blood viremia assessed by polymerase chain reaction (PCR) as well as the diffusing capacity of carbon monoxide (DLCO) in examined pulmonary function tests (PFT). Group [A] included 100 patients with low or moderate viremia and showing normal or low to moderate $D L_{c o}$ decline (>50\%). Group [B] included 100 patients with high viremia and showing normal or low to moderate $\mathrm{D} \mathrm{L}_{\mathrm{CO}}$ decline (> 50\%). Group [C] included 100 patients with high viremia and showing a restrictive DLCO decline pattern $(<50 \%)$. The study included 182 males and 118 females with a ratio of 3:2, while the age ranged between 40 and 70 years (mean age of 55 years). No ILD was found among the group [A] patient. Meanwhile, $27 \%$ of patients in the group [B] showed a non-fibrotic pattern of ILD and 50\% of patients in the group [C] showed a fibrotic pattern of ILD. Among patients in group [B] and group [C] together, 77 patients showed ILD accounting for 38.5\%.
\end{abstract}

Conclusion: In concordance with the results of the previous clinicopathological and geno-physiological studies, our HRCT results further established a mild to moderate relation between active hepatitis and ILD regardless of the pulmonary functions. The fibrotic pattern of ILD with poor response to therapy and poor prognosis was found in those patients with concomitant restrictive PFT and rapidly progressive symptoms.

\section{Background}

Hepatitis is inflammation of the liver which may be caused by several infectious and non-infectious causes. Late diagnosis usually took place and the process will be progressing to fibrosis, cirrhosis, and hepatocellular cancer [1]. Egypt is one of the most prevalent countries in the world in the hepatitis $\mathrm{C}$ virus $(\mathrm{HCV})$ infection with a great burden on health care services. Hence, treatment

\footnotetext{
* Correspondence: Sweetjomana36@hotmail.com

'Department of Radio-diagnosis, Faculty of Medicine, University of

Alexandria, Alexandria, Egypt

Full list of author information is available at the end of the article
}

and elimination of which have become a national priority [2]. Hepatitis C virus (HCV) is serious public health problem with limited lines of treatments including pegylated interferon (IFN) and ribavirin [3]. HCV is considered as hepato-tropic and lymphotropic virus resulting in hepatic and extra-hepatic diseases [4]. HCV can affect the lung either indirectly (more common) or directly (less common). The indirect effects included pulmonary hypertension, corpulmonal, and hepato-pulmonary syndrome while the direct effects included exacerbation of pre-existing chronic obstructive pulmonary disease

\section{Springer Open}

(c) The Author(s). 2020 Open Access This article is licensed under a Creative Commons Attribution 4.0 International License, which permits use, sharing, adaptation, distribution and reproduction in any medium or format, as long as you give appropriate credit to the original author(s) and the source, provide a link to the Creative Commons licence, and indicate if changes were made. The images or other third party material in this article are included in the article's Creative Commons licence, unless indicated otherwise in a credit line to the material. If material is not included in the article's Creative Commons licence and your intended use is not permitted by statutory regulation or exceeds the permitted use, you will need to obtain permission directly from the copyright holder. To view a copy of this licence, visit http://creativecommons.org/licenses/by/4.0/. 
(COPD) and interstitial lung diseases (ILD) including interstitial pneumonias (IIPs) and lung fibrosis [5].

Pathological wise; HCV can cause chronic activation in the immune system because it is lymphotropic with consequent direct tissue damage attributed to HCVRNA or deposition of the immunoglobulin immune complex [6]. This pathogenic correlation has been evidenced by several observations. Several shreds of evidences for this pathological relation are reported including that many patients with idiopathic pulmonary fibrosis (IPF) had elevated HCV markers. Bronchoalveolar lavage (BAL) revealed high neutrophils and lymphocytes. Lung biopsy revealed HCV genome. HCV hepatitis treated with interferon showed IPF in serial follow-ups [7], also cryptogenic organizing pneumonia (COP) and sarcoidosis were reported [6].

Several types of interstitial lung diseases were described in patients with active hepatitis. These include predominantly fibrotic diseases, mainly IPF. There are other non-fibrotic diseases such as non-specific interstitial pneumonia (NSIP). COP, one of interstitial pneumonias, as well as sarcoidosis, was reported with interferon therapy $[6,7]$. HRCT currently plays a major role in the characterization of IIP with its major advantage as a non-invasive examination, also to differentiate them from non-interstitial diseases with lung fibrosis [8]. New guidelines stated that multi-detector computed tomography (MDCT) can diagnose usual interstitial pneumonia (UIP) without the need for tissue confirmation [9]. Still, for the non-UIP patterns, there is a dilemma; hence, communication and collaboration between pulmonologists, radiologists, and pathologists is mandatory to yield a more specific diagnosis $[10,11]$.

The majority of basic researches, that discovered a relation between viral hepatitis and ILD, were mainly pathophysiological and only a few radiological researches were done. This study aims to prove this relation radiologically and correlate this relation to disease activity (blood viremia) then describe which patterns are more common to be seen. This will definitely affect patient management and prognosis.

\section{Methods}

The study was carried out from January 2017 till January 2020. It was conducted prospectively on 300 patients with a known history of viral hepatitis. The principals of ethics were respected and the rights of participants were protected. Committee of Ethics in our Faculty of Medicine approved this research.

\section{Medical record review}

All patients were subjected to thorough history taking and clinical examination. PCR and PFTs were done to all patients. They were divided into three groups of patients according to blood viremia assessed by polymerase chain reaction (PCR) as well as diffusing capacity of carbon monoxide $\left(\mathrm{DL}_{\mathrm{CO}}\right)$ in examined pulmonary function tests (PFT). Group [A] included 100 patients with low or moderate viremia and showing normal or low to moderate $\mathrm{DL}_{\mathrm{CO}}$ decline $\left(\mathrm{DL}_{\mathrm{CO}}>50 \%\right)$. Group $[\mathrm{B}]$ included 100 patients with high viremia and showing normal or low to moderate $\mathrm{DL}_{\mathrm{CO}}$ decline $\left(\mathrm{DL}_{\mathrm{CO}}>50 \%\right)$. Group $[\mathrm{C}]$ included 100 patients with high viremia and showing a restrictive $\mathrm{DL}_{\mathrm{CO}}$ decline pattern $\left(\mathrm{DL}_{\mathrm{CO}}<50 \%\right)$.

Exclusion criteria were the following: (1) previous lung co-morbidity, pre-existing asthma, or COPD; (2) previous data about indirect $\mathrm{HCV}$ effects including pulmonary hypertension and corpulmonale; (3) Kypho-scoliotic dorsal spine configuration which may result in false PFT results. The reason for exclusion was to exclude any disease which will cause secondary pulmonary fibrosis other than hepatitis and interfere with PFTs such as (1) combined pulmonary fibrosis and emphysema (CPEF) or (2) secondary interstitial pulmonary fibrosis sequel to corpulmonale with chronic interstitial pulmonary edema or (3) changes in the lung volume with chronic fibroatelectasis secondary to kyphoscoliosis.

Further investigations and laboratory data were used to help diagnosis and characterization of ILD predominant pattern include (1) broncho-alveolar lavage (BAL) with cytology, (2) Bronchoscopy with biopsy from mediastinal lymphadenopathy as well as (3) video-assisted thoracoscopy (VATS) with direct lung biopsy.

\section{HRCT technique and acquisition}

Chest HRCT was done to all patients using multidetector CT; SOMATOM Emotion 16 and Siemens SOMATOM Sensation 64 (Germany), Toshiba Aquilion 64 and 128 MSCT (USA), and GE LightSpeed Plus 4 slice CT scanner (USA). Volumetric acquisition of HRCT data acquired during inspiration in the supine position with a high-spatial-frequency reconstruction algorithm obtained from the root of the neck down to the level of the adrenal glands.

Scanning parameters were the following: volumetric high-spatial-frequency kernel algorithm, $1.25 \mathrm{~mm}$ slice thickness, $1 \mathrm{~mm}$ detector collimation, $\mathrm{kVp}$ (80-120), and $\mathrm{mA}(120-240 \mathrm{~mA})$ per slice. Thin slices were sent to workstations, and MPR was available in axial, sagittal, and coronal planes. Min-IP used for mosaic attenuation changes while MIP used for nodular changes.

\section{HRCT reading}

The following HRCT characteristics were assessed independently in each disease by three consultant radiologists (having 16, 17, and 18 years of experience in chest imaging, particularly ILD) and they were informed with the clinical data. 
- Lobar distribution: including upper versus lower predominance.

- Axial distribution: including axial peri-bronchial versus peripheral sub-pleural predominance.

- Mosaic pattern: including ground glass opacities (GGO), mosaic perfusion or air trapping, ground glass/mosaic perfusion ratio, and "head cheese pattern."

- Reticular pattern: including architectural distortion, reticulation, interlobular septal thickening, traction bronchiectasis; and bronchiolectasis, honeycombing, GG, and super-imposed smooth interlobular septal thickening "crazy-paving pattern."

- Nodular pattern: including peri-lymphatic nodules and centrilobular nodules.

- The semi-quantitative visual method was used to compare which pattern of ILD is predominant: whether reticular fibrotic or attenuation/nodular non-fibrotic. This method [12] divides the lungs into three levels: upper (above carina), lower (below right phrenic highest point), and middle level (in between). A horizontal line is drawn dividing each lung around $50 \%$. Then, a vertical line is drawn perpendicular leaving around 25\% of each lung. Then, every part is divided into five sections (each around 5\%). Each section will be examined to see which pattern is predominant? Whether the fibrotic reticular pattern or non-fibrotic attenuation/nodular pattern (Fig. 1).

\section{Software reconstruction methods were crucial}

MPR used for disease distribution analysis. MIP was helpful for the detection of lung nodules and magnifying fibrotic changes. Min-IP was very helpful for the evaluation of mosaic attenuation patterns (GGO and mosaic perfusion), also evaluation of bronchiolectasis and honeycombing.

\section{Statistical analysis}

The prevalence rate of HRCT findings was estimated as the percentage of patients showing each radiological abnormality. Data were compared using a chi-square test and $p$ value $<0.05$ was considered statistically significant. Online chi-square and $p$ value calculators were used (https://www.socscistatistics.com/tests/). Inter-Observer Agreement (IOA) co-efficient was calculated using Cohen's Kappa test.

\section{Results}

This study included 300 patients with viral hepatitis complaining mainly from different grades of dyspnea. They were 182 males and 118 females with ratio 3:2, while age ranged between 40 and 70 years (mean age 55 years). All patients were subjected to history taking and clinical examination.

Table 1, Figs. 2 and 3 will summarize the following results:

\section{Regarding group $[\mathrm{A}]$}

CT results were unremarkable in 62 patients. No ILD was found.

\section{Regarding group [B]}

CT results were unremarkable in 28 patients. Nonfibrotic ILD was found in 27 patients.

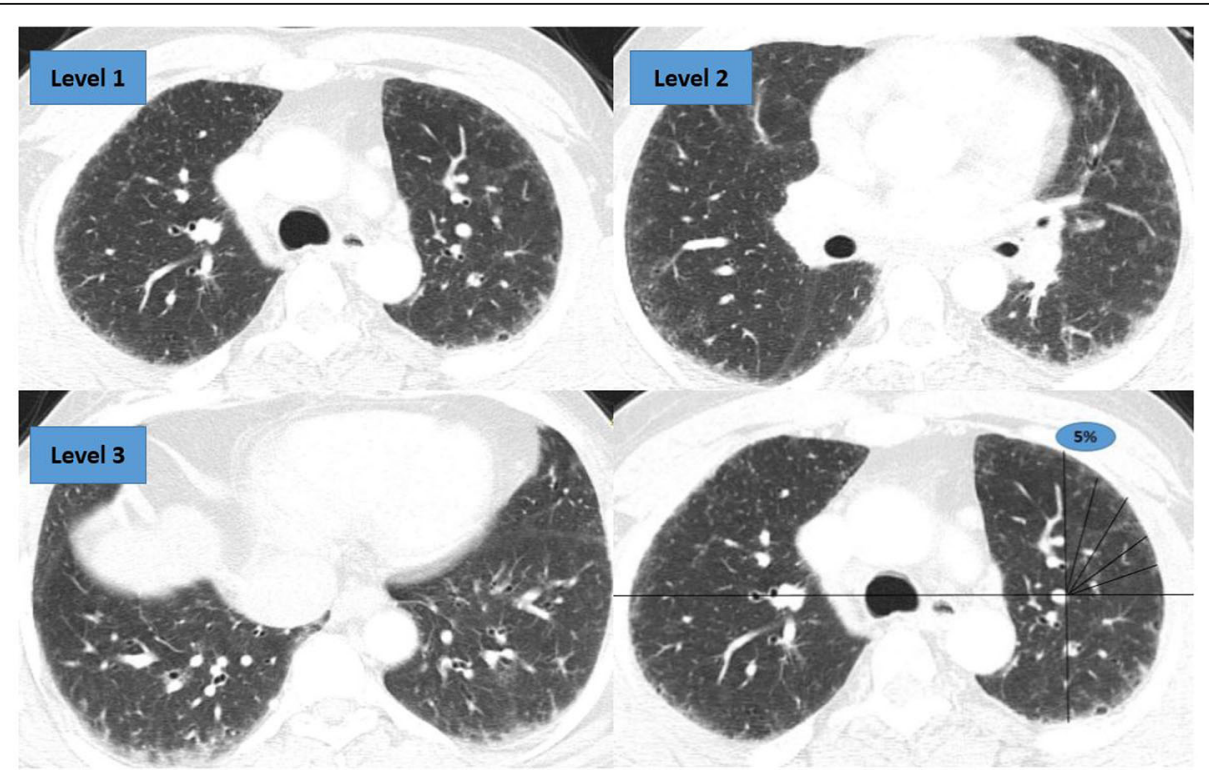

Fig. 1 Semi-quantitative visual method for assessment of predominant ILD pattern: levels of HRCT and slices quantification 
Table 1 Summary of results in group (B) and (C) including ILD characterization, \% of patients involved, radiological signs, and further investigatory tools

\begin{tabular}{|c|c|c|c|c|c|c|c|c|c|}
\hline \multirow[t]{2}{*}{ ILD } & \multirow[t]{2}{*}{$\begin{array}{l}\text { Predominant pattern } \\
\text { in visual score }\end{array}$} & \multirow{2}{*}{\multicolumn{2}{|c|}{ Final diagnosis }} & \multicolumn{4}{|c|}{ Group [B]: high viremia } & \multicolumn{2}{|c|}{$\begin{array}{l}\text { Group [C]: high viremia, } \\
\text { restrictive PFT }\end{array}$} \\
\hline & & & & No $\%$ & $\begin{array}{l}\text { Radiological } \\
\text { signs }\end{array}$ & $\begin{array}{l}\text { Confirming } \\
\text { investigation }\end{array}$ & No $\%$ & Radiological signs & $\begin{array}{l}\text { Confirming } \\
\text { investigation }\end{array}$ \\
\hline \multirow[t]{4}{*}{$\begin{array}{l}\text { Fibrotic } \\
\text { ILD }\end{array}$} & \multirow[t]{4}{*}{ Reticular pattern } & \multirow{2}{*}{$\begin{array}{l}\text { Interstitial } \\
\text { pneumonia } \\
\text { (IP) }\end{array}$} & UIP & \multirow{4}{*}{\multicolumn{3}{|c|}{ Absent }} & 17 & $\begin{array}{l}\text { PF and "honey } \\
\text { combing" }\end{array}$ & No need \\
\hline & & & $\begin{array}{l}\text { Fibrosing } \\
\text { NSIP }\end{array}$ & & & & 19 & $\begin{array}{l}\mathrm{PF} \text { and traction } \\
\text { bronchiectasis/ } \\
\text { bronchiolectasis }\end{array}$ & $\begin{array}{l}\text { BAL ( } \uparrow \text { neutrophils, } \\
\text { eosinophils and } \\
\text { lymphocytes) }\end{array}$ \\
\hline & & \multirow[t]{2}{*}{$\begin{array}{l}\text { Non-IP } \\
\text { (mimic) }\end{array}$} & Chronic HP & & & & 10 & $\begin{array}{l}\text { PF or septal } \\
\text { thickening with } \\
\text { "head cheese" }\end{array}$ & $\begin{array}{l}\text { BAL ( } \uparrow \text { mast cells and } \\
\text { lymphocytes with } \\
\text { macrophages) }\end{array}$ \\
\hline & & & $\begin{array}{l}\text { Sarcoidosis } \\
\text { (stage II:IV) }\end{array}$ & & & & 4 & $\begin{array}{l}\text { Peri-bronchial } \\
\text { fibro-nodular } \\
\text { changes }\end{array}$ & $\begin{array}{l}\text { Bronchoscopy, } \\
\text { thoracoscopy, and } \\
\text { biopsy }\end{array}$ \\
\hline \multirow{7}{*}{$\begin{array}{l}\text { Non- } \\
\text { fibrotic } \\
\text { ILD }\end{array}$} & \multirow[t]{7}{*}{$\begin{array}{l}\text { Attenuation and } \\
\text { nodular pattern }\end{array}$} & \multirow{4}{*}{$\begin{array}{l}\text { Interstitial } \\
\text { pneumonia } \\
\text { (IP) }\end{array}$} & $\begin{array}{l}\text { Cellular } \\
\text { NSIP }\end{array}$ & 10 & Sub-pleural G & & No need & \multirow[t]{7}{*}{ Absent } & \\
\hline & & & COP & 3 & Peri-bronchia & "Atol sign" & $\begin{array}{l}\text { BAL }(\uparrow \\
\text { lymphocytes } \\
20-40 \% \text { and } \\
\downarrow \text { CD4/CD8 } \\
\text { ratio is } 0.3-0.5)\end{array}$ & & \\
\hline & & & CEP & 2 & Sub-pleural ", & Atol sign" & $\begin{array}{l}\text { BAL } \\
(\uparrow \text { eosinophils } \\
40-80 \% \text { and } \uparrow \\
\text { CD4/CD8 ratio) }\end{array}$ & & \\
\hline & & & LIP & 1 & GG and cysts & & $\begin{array}{l}\text { BAL } \\
\text { ( } \uparrow \text { lymphocytes) }\end{array}$ & & \\
\hline & & \multirow[t]{3}{*}{$\begin{array}{l}\text { Non-IP } \\
\text { (mimic) }\end{array}$} & $\begin{array}{l}\text { Sub-acute } \\
\text { HP }\end{array}$ & 8 & $\begin{array}{l}\text { Diffuse centri } \\
\text { nodules and }\end{array}$ & $\begin{array}{l}\text { lobular GG } \\
\text { "head cheese" }\end{array}$ & $\begin{array}{l}\text { Clinical } \\
\text { diagnosis }\end{array}$ & & \\
\hline & & & $\begin{array}{l}\text { Alveolar } \\
\text { proteinosis }\end{array}$ & 1 & "Crazy paving & & $\begin{array}{l}\text { BAL ( } \uparrow \text { protein } \\
\text { SP-A and SP-D } \\
\text { and lg-G) }\end{array}$ & & \\
\hline & & & $\begin{array}{l}\text { Sarcoidosis } \\
\text { (stage I) }\end{array}$ & 2 & $\begin{array}{l}\text { Bilateral hilar } \\
\text { enlargement }\end{array}$ & and nodal & $\begin{array}{l}\text { Bronchoscopy } \\
\text { and biopsy }\end{array}$ & & \\
\hline \multicolumn{4}{|l|}{ Total } & \multicolumn{4}{|c|}{ 27\% (mild relation) } & \multicolumn{2}{|c|}{ 50\% (moderate relation) } \\
\hline
\end{tabular}

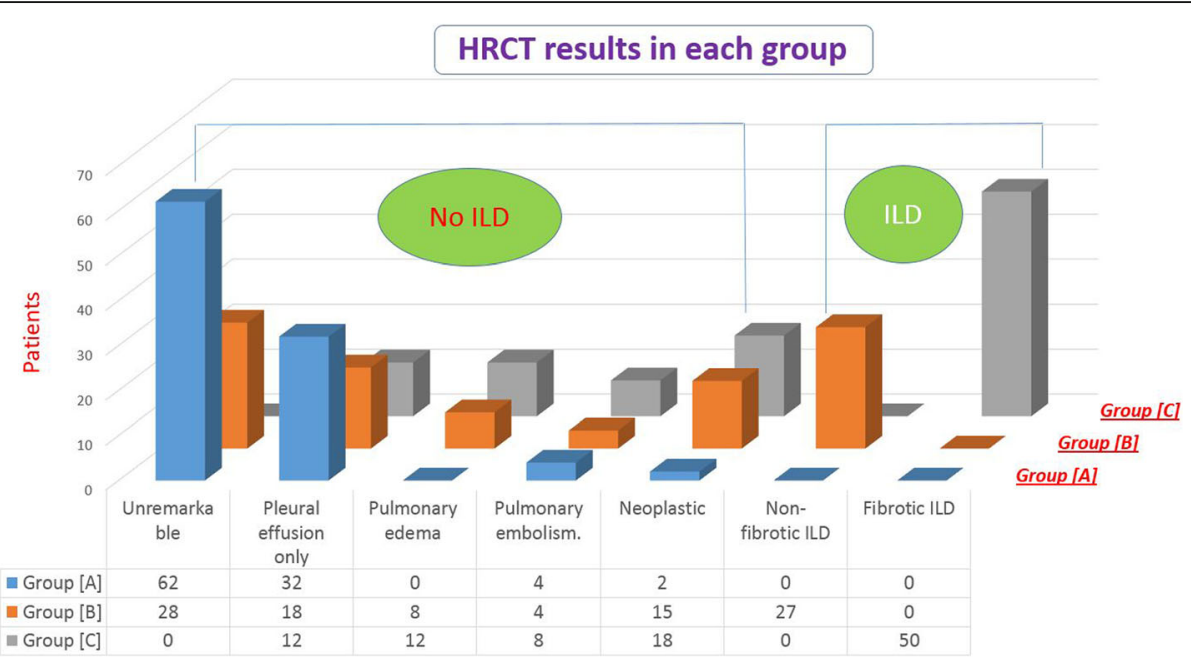

Fig. 2 Chart summarizing results of HRCT in each group of examined patients 


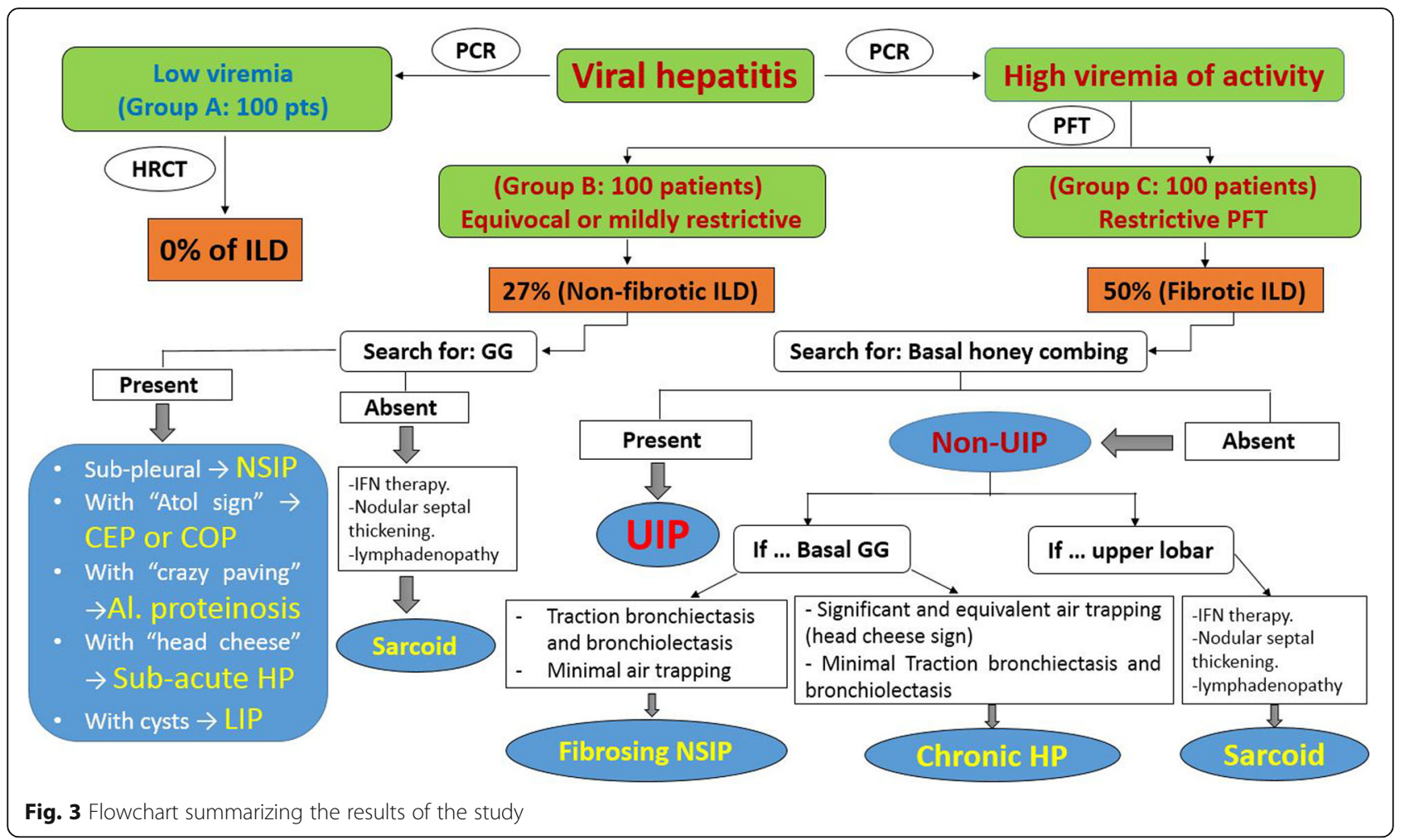

Further characterization of the non-fibrotic pattern of ILD was performed based on radiological and further investigatory data; all patients showed higher attenuation and nodular pattern scores. Interstitial pneumonia (IP) was found in 16 patients and sub-classified as mentioned in (Table 1). Non-interstitial pneumonia (non-IP) was found in 11 patients and sub-classified as mentioned also in (Table 1).

\section{Regarding the diagnostic criteria and methods used to confirm the diagnosis}

Those patients with NSIP showed sub-pleural groundglass attenuation pattern (Fig. 4). Those patients with $C O P$ showed peri-bronchial patches of central ground- glass opacities and peripheral organized consolidated material (Atol sign) (Fig. 5). All findings were found shortly after therapy, suggesting the relation to treatment (mainly IFN). A very good response to corticosteroid was noticed in the next follow-ups. Those patients with $C E P$ showed peripheral sub-pleural ground glass patches with a peripheral sclerotic rim. Those patients with LIP showed scattered air-filled cysts on a background of faint ground-glass opacity. Five patients out of 10 with sub-acute HP showed widely dispersed centrilobular ground-glass nodules. Meanwhile, other seven patients showed alternating areas of air trapping and ground-glass attenuation (head cheese pattern) (Fig. 6); of them, two patients showed mixed nodule and head

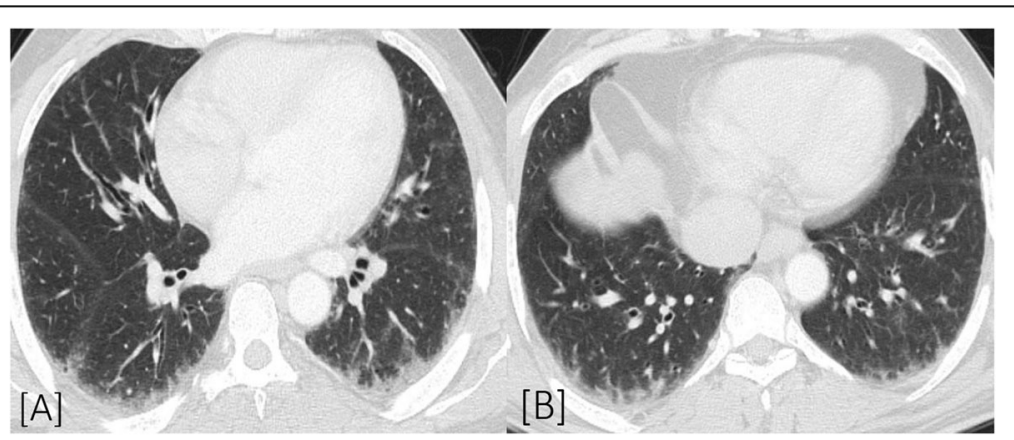

Fig. 4 A 51-year-old patient with active hepatitis, normal PFT, and mild dyspnea. a, b Axial HRCT showing bilateral sub-pleural GGO without appreciable reticular changes. Cellular NSIP 


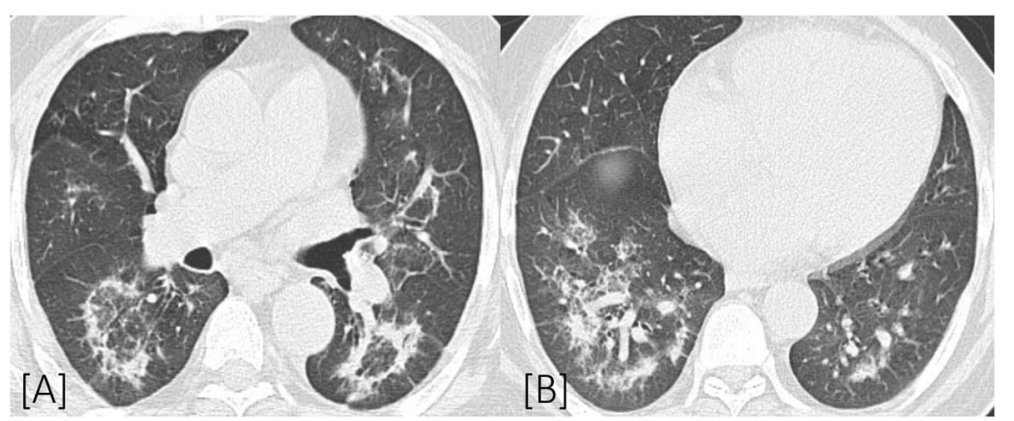

Fig. 5 A 42-year-old patient with active hepatitis, normal PFT complaining from progressive dyspnea following therapy. a, b Axial HRCT chest (lung window) showing bilateral patchy areas of air trapping admixed with GGO "head cheese pattern" without appreciable reticular changes. COP

cheese results. One patient with alveolar proteinosis showed diffuse ground-glass attenuation pattern with smooth septal thickening (crazy-paving pattern) (Fig. 7). Those patients with stage I sacroid disease showed bilateral hilar and mediastinal enlarged lymph nodes. The history of IFN therapy is positive. All methods for diagnosis confirmation were summarized in (Table 1).

\section{Regarding group $[\mathrm{C}]$}

Fibrotic ILD pattern was found in 50 patients. Nonfibrotic ILD pattern was not seen. Further characterization of the fibrotic pattern of ILD was performed based on radiological and further investigatory data; all patients showed higher reticular fibrotic pattern score. Usual interstitial pneumonia (UIP) was depicted in 17 patients, fibrosing NSIP was depicted in 19 patients, chronic HP was depicted in ten patients while sarcoidosis (stage II: IV) was depicted in four patients.

\section{Regarding the diagnostic criteria and methods used to confirm the diagnosis}

Those patients with UIP showed interstitial thickening and classic (honeycombing bronchiectasis) (Fig. 8). Those patients with fibrosing NSIP showed interstitial thickening and traction bronchiectasis/bronchiolectasis without honeycombing (Fig. 9). Those patients with chronic HP showed head cheese pattern with superadded interstitial fibrosis. Those patients with sarcoidosis showed isolated upper and mid zonal peri-bronchial fibro-nodular changes or mixed with hilar and mediastinal nodal enlargement (Fig. 10). All methods for diagnosis confirmation were summarized in (Table 1).

\section{Regarding statistical relation}

Image analysis was done for each group separately by three observers and inter-observer differences in this study were negligible as Inter-Observer Agreement (IOA) Co-efficient (Cohen's K) was calculated (100\%, $94 \%, 96 \%$ in groups A, B, and C, respectively).

Regarding the hypothetical connection between "ILD and active viral hepatitis depicted by high HCV viremia"

Chi-squared critical value (CV) was calculated with Yates correction $(=10.2207)$ then $p$ value with calculated (0.001389). This significant $p$ value $<0.05$ confirms this connection.

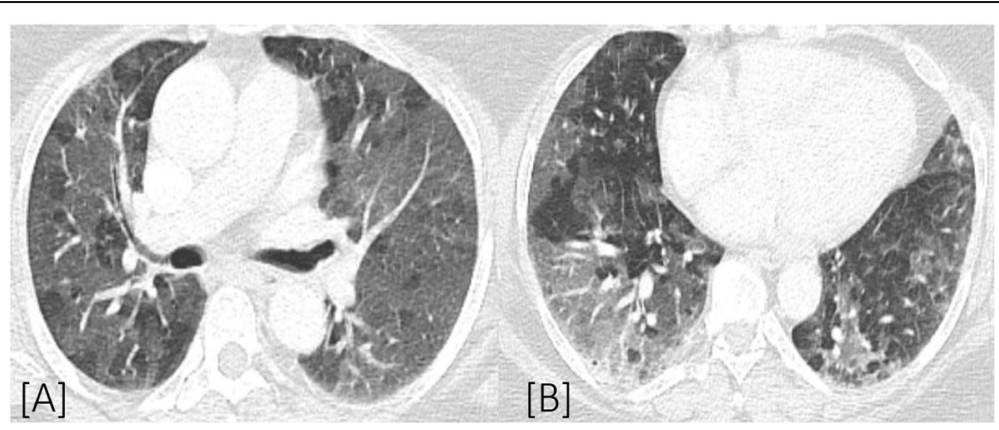

Fig. 6 A 52-year-old patient with active hepatitis, normal PFT complaining from progressive dyspnea. a, b Axial HRCT chest (lung window) showing bilateral patchy areas of air trapping mixed with GGO "head cheese pattern" without appreciable reticular changes. Sub-acute HP 


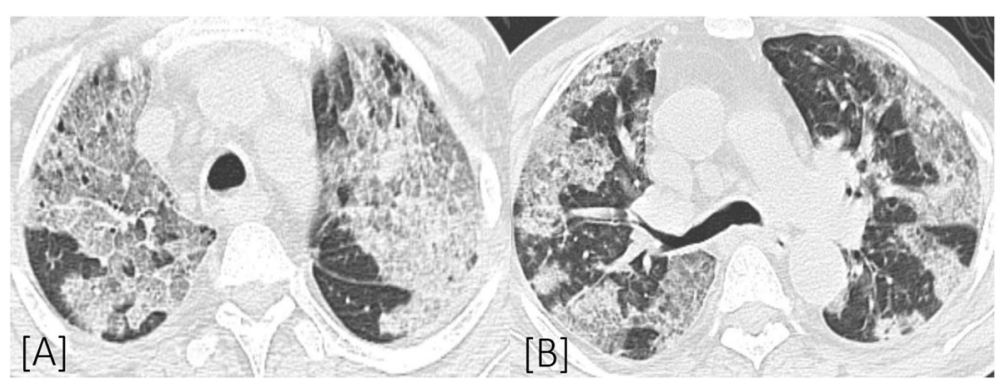

Fig. 7 A 48-year-old patient with active hepatitis, normal PFT complaining from progressive dyspnea. a, b Axial HRCT chest (lung window) showing bilateral wide spread areas of GGO admixed with inter-lobular septal thickening "crazy-paving pattern." Alveolar proteinosis

Regarding the hypothetical connection between "nonfibrotic ILD and active viral hepatitis depicted by high HCV viremia"

Chi-square critical value $(\mathrm{CV})$ was calculated $(=31.213)$ then $p$ value with calculated $(<0.0001)$. This significant $p$ value $<0.05$ confirms this connection.

Regarding the hypothetical connection between "fibrotic ILD and active viral hepatitis depicted by high HCV viremia and associated with restrictive PFT"

Chi-square critical value (CV) was calculated $(=66.667)$ then $p$ value with calculated $(<0.0001)$. This significant $p$ value $<0.05$ confirms this connection.

\section{Regarding the prevalence rate of the diseases}

Among group [B] patients, prevalence rate of "non-fibrotic ILD" was 27\%. Among group [C] patients, the prevalence rate of "fibrotic ILD" was 50\%. Among patients in group [B] and group [C] together, the prevalence rate of ILD was $38.5 \%$.

\section{Discussion}

The reports which suggested the relation between viral hepatitis and pulmonary diseases have recently increased in number. Furthermore, recent studies of an immune response to $\mathrm{CD} 8+\mathrm{T}$ lymphocytes and inflammatory cytokines are currently encouraging the presence of a connection between chronic HCV infection and pathogenesis of ILDs $[6,7]$.

\section{ILDs were not detected in group $[A]$ patients}

Sixty-two percent of patients showed unremarkable CT results while $32 \%$ showed pleural effusion. El-Badrawy et al. [13] performed this study on different groups of patients including those with low or moderate viremia and also did not depict ILD among them.

\section{ILDs were depicted in $\mathbf{2 7 \%}$ of group [B] patients}

All of them showed non-fibrotic pattern with predominant attenuation and nodular rather than reticular changes. Cellular type of NSIP and sub-acute type hypersensitivity pneumonitis were the most common types, accounting for $37 \%$ and $29.6 \%$, respectively; the former presented by sub-pleural GGOs while the latter showed mixed GGO and air trapping (head cheese) with or without centrilobular ground-glass nodules. COP was found in $11 \%$ of patients, and all of them presented shortly after immunotherapy; Atol sign was characteristic. CEP and nodal sarcoidosis were both found in $7.4 \%$ of patients; the latter showed a positive recent history of immunotherapy. LIP and alveolar protreinosis were
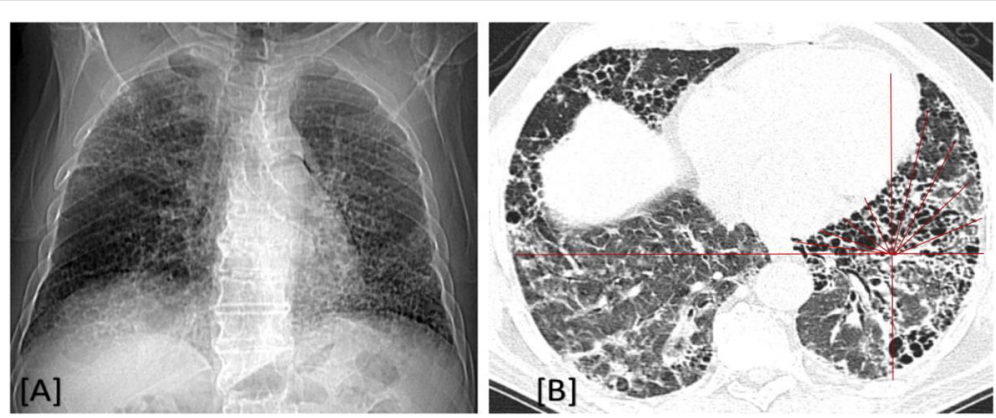

Fig. 8 A 55-year-old patient with active hepatitis complaining from progressive dyspnea with restrictive PFT. a X-ray chest PA view. b Axial CT chest (lung window). Both showing extensive fibrotic changes, and honey combing bronchiectasis is more pronounced in lower lung zones. Slices visual semi-quantitative assessment of fibrosis done in CT. UIP pattern 


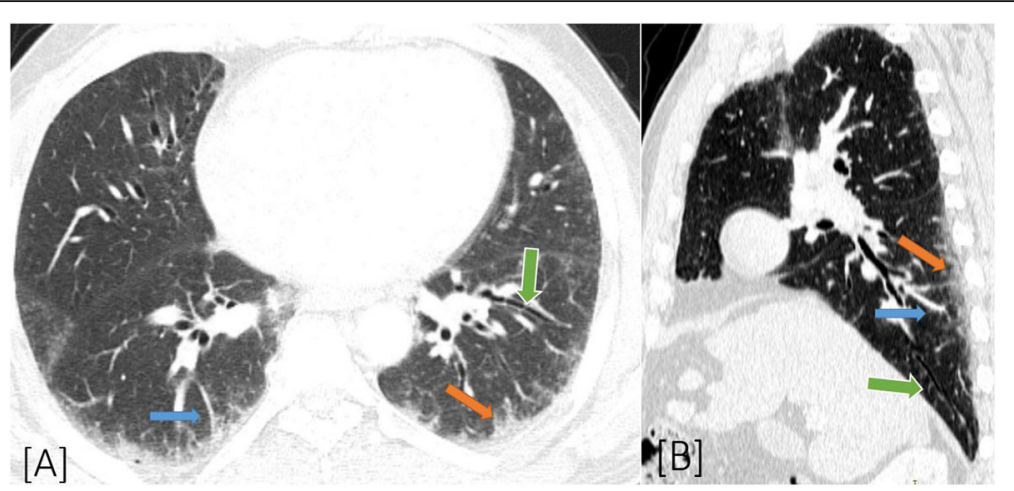

Fig. 9 A 47-year-old patient with active hepatitis complaining from progressive dyspnea with mild degree of restrictive PFT. a, b Axial and sagittal HRCT chest (lung window) showing sub-pleural GGO (orange colored arrow) with mild reticular thickening (blue colored arrow) and traction bronchiolectasis (green colored arrow). Fibrosing NSIP pattern

depicted only in $3.7 \%$ of patients each; the latter showed characteristic (crazy-paving pattern).

Segna et al. [14]. simply stated that HCV patients showed a high incidence for the development of ILD and El-Badrawy et al. [13] also declared the presence of ILD and variable idiopathic interstitial pneumonias (IIPs) among those patients with high viremia.

Similar to our findings, Hodnett et al. [15] stated that sub-pleural ground-glass attenuation was classic for cellular type of NSIP, while "Atol sign" was described for COP and "crazy-paving pattern" was described for alveolar proteinosis. Also, Lynch et al. [16] similarly clarified that "head cheese" pattern in HP was attributed to obliterative bronchiolitis.

Fibrotic ILD was found in 50\% of group [C] patients which had high viremia in PCR and restrictive PFT. They presented with predominant reticular changes and fibrosis sequel including traction bronchiectasis/bronchiolectasis and honeycombing with architectural distortion. Fibrosing type of NSIP and UIP/IPF were the main detected types accounting for $38 \%$ and $34 \%$, respectively; the latter showed characteristic honeycombing. Chronic
HP was also found in 20\% of involved patients with background of head cheese pattern and fibrosis. Postmanagement parenchymal fibrosing type of sarcoidosis was found only in $8 \%$ of them.

Our results agreed with findings of Hodnett et al. [15] as traction bronchiectasis and bronchiolectasis with subpleural ground-glass attenuation were characteristic in fibrosing NSIP, while characteristic honeycombing predominated UIP patients. Also, they agreed with findings of Abehsera et al. [17] as fibrosing sarcoidosis typically affects upper and middle lung zones with parenchymal distortion and peri-lymphatic nodules.

Our results match that of Saleh et al. [18], Hassan et al. [19], and Rabea et al. [20]; they all correlate the incidence of IPF in HCV patients to their hypoxemia level in $\mathrm{ABG}$ and more restrictive pattern of pulmonary functions. El Badrawy et al. [13] also correlate it to the degree of viral activity using PCR viremia level.

Among patients in group $[\mathrm{B}]$ and group $[\mathrm{C}]$ together, $38.5 \%$ of patients showed ILD. Based on the calculated chi-square critical value $(\mathrm{CV}), p$ values, and prevalence rates, a mild hypothetical connection between non-

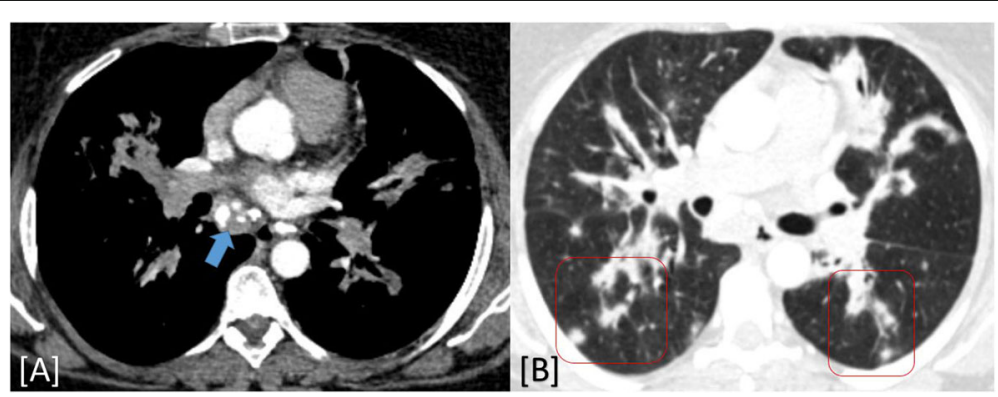

Fig. 10 A 44-year-old patient with active hepatitis and restrictive PFT complaining from progressive dyspnea after 3 months from IFN therapy complaining from progressive dyspnea and restrictive PFT. $\mathbf{a}$, b Axial HRCT chest mediastinal and lung window showing sub-carinal node with calcific foci (blue arrow) together with confluent peri-bronchial fibro-consolidative patches with parenchymal distortion and peri-lymphatic nodules (red-colored squares). Fibrosing sarcoid disease 
fibrotic ILD and high HCV viremia was statistically confirmed. A moderate hypothetical connection between fibrotic ILD and high HCV viremia associated with restrictive pulmonary functions was statistically confirmed. A mild to moderate hypothetical connection between ILD and active viral hepatitis depicted by high $\mathrm{HCV}$ viremia was statistically confirmed regardless of the result of the pulmonary function tests.

The most important merit of this research and used techniques were the following: (1) proved relation not only between HCV and ILD but also between blood viremia and predominant pattern of ILD using PCR, PFT, and HRCT; (2) characterization of predominant ILD pattern using HRCT which could replace lung biopsy and save patients from its hazards; (3) semiquantitative method for assessment of degree lung fibrosis help in disease characterization and patient outcome determination.

The study was mildly limited by the overlap of the pulmonary function parameters rendering some results equivocal hence DLCO was mainly used.

\section{Conclusion}

In concordance with the results of the previous clinicopathological and genophysiological studies, our HRCT results furtherly established a mild to moderate connection between active hepatitis and ILD regardless of the pulmonary functions. The fibrotic pattern of ILD with poor response to therapy and poor prognosis was found in those patients with concomitant restrictive PFT and rapidly progressive symptoms.

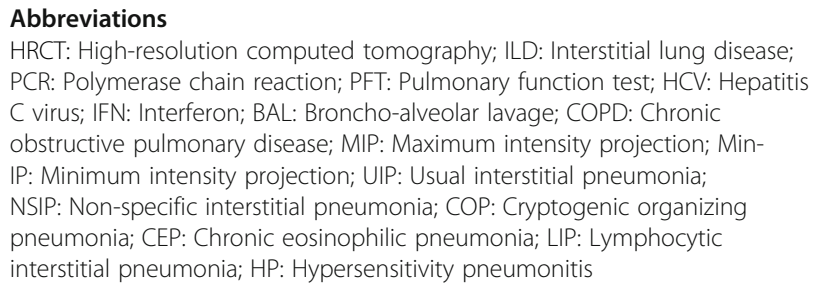

HRCT: High-resolution computed tomography; ILD: Interstitial lung disease; PCR: Polymerase chain reaction; PFT: Pulmonary function test; HCV: Hepatitis $C$ virus; IFN: Interferon; BAL: Broncho-alveolar lavage; COPD: Chronic obstructive pulmonary disease; MIP: Maximum intensity projection; MinIP: Minimum intensity projection; UIP: Usual interstitial pneumonia; NSIP: Non-specific interstitial pneumonia; COP: Cryptogenic organizing pneumonia; CEP: Chronic eosinophilic pneumonia; LIP: Lymphocytic interstitial pneumonia; HP: Hypersensitivity pneumonitis

\section{Acknowledgements}

Not applicable.

\section{Authors' contributions}

Each author has made specific substantial contributions. Radiological evaluation of chest HRCT findings, data analysis, and discussion were done by three consultant radiologists ( $A S, A E, M H)$, while correlation to medical and pulmonary functions tests' data was done by consultant chest medicine (HG). All authors read and approved the final and revised manuscript. All authors agreed both to be personally accountable for the authors' own contributions and to ensure that questions related to the accuracy or integrity of any part of the work, even ones in which the author was not personally involved, are appropriately investigated, resolved, and the resolution is documented in the literature.

\section{Funding}

None (authors personal contribution).

\section{Availability of data and materials}

The datasets used and/or analyzed during the current study are available from the corresponding author on reasonable request.

\section{Ethics approval and consent to participate}

The medical ethics were considered and respected. Study was ethically approved by Institutional Ethics Committee. All patients included in this research gave verbal informed consent to participate. Ethics committee has approved verbal informed consent of large number of patients group whose data has free open access as absolutely non-touching patient confidentiality or personal interests. [IRB no. (00012098), FWA no. (00018699), Serial no. (0304610)].

\section{Consent for publication}

All patients included in this research gave verbal informed consent to publish the data contained within this study.

\section{Competing interests}

None

\section{Author details}

${ }^{1}$ Department of Radio-diagnosis, Faculty of Medicine, University of Alexandria, Alexandria, Egypt. ${ }^{2}$ Department of Chest diseases, Faculty of Medicine, University of Alexandria, Alexandria, Egypt.

Received: 20 April 2020 Accepted: 6 August 2020

Published online: 24 August 2020

\section{References}

1. Lazarus JV, Picchio C, Dillon JF, Rockstroh JK, Weis N, Buti M (2019) Too many people with viral hepatitis are diagnosed late-with dire consequences. Nat Rev Gastroenterol Hepatol 19:1

2. Omran D, Alboraie M, Zayed RA, Wifi MN, Naguib M, Eltabbakh $M$ et al (2018 Oct 14) Towards hepatitis C virus elimination: Egyptian experience, achievements and limitations. World J Gastroenterol 24(38):4330

3. Abi-Nassif S, Mark EJ, Fogel RB, Hallisey RK Jr (2003) Pegylated interferon and ribavirin-induced interstitial pneumonitis with ARDS. Chest 124(1):406410

4. Kanazawa H, Yoshikawa J (2004 Jun 1) Accelerated decline in lung function and impaired reversibility with salbutamol in asthmatic patients with chronic hepatitis C virus infection: a 6-year follow-up study. Am J Med 116(11):749-752

5. Simonneau G, Montani D, Celermajer DS et al (2019) Haemodynamic definitions and updated clinical classification of pulmonary hypertension. Eur Respir J 53:1801913

6. Odorizzi PM, Wherry EJ (2013) Immunology. An interferon paradox. Science 340(6129):155-156

7. Hegade VS, Sood R, Saralaya D, Moreea S (2013) Pulmonary complications of treatment with pegylated interferon for hepatitis $C$ infection-two case reports. Ann Hepatol 12(4):629-633

8. Palmucci S, Roccasalva F, Puglisi S, Torrisi SE, Vindigni V, Mauro LA et al (2014) Clinical and radiological features of idiopathic interstitial pneumonias (IIPS): a pictorial review. Insights into imaging 5(3):347-364

9. Raghu G, Collard HR, Egan JJ, Martinez FJ, Behr J, Brown KK et al (2011 Mar 15) An official ATS/ERS/JRS/ALAT statement: idiopathic pulmonary fibrosis: evidence-based guidelines for diagnosis and management. Am J Respir Crit Care Med 183(6):788-824

10. Gruden JF (2016) CT in Idiopathic Pulmonary Fibrosis: Diagnosis and Beyond. AJR 206:495-507

11. Ryu JH, Moua T, Azadeh N, Baqir M, Yi ES (2016) Current concepts and dilemmas in idiopathic interstitial pneumonias. F1000Research 5:2661

12. Sánchez RP, Fernández-Fabrellas E, Samper GJ, Montañana ML, Vilar LN (2018) Visual HRCT Score to Determine Severity and Prognosis of Idiopathic Pulmonary Fibrosis. Int J Respir Pulm Med 5:084

13. El Badrawy ES, Abdalla TM, El Shahat HM (2018 Jun 1) The Relation between Interstitial Lung Disease and Chronic HCV Infection. Afro-Egyptian Journal of Infectious and Endemic Diseases 8(2):74-80

14. Segna D, Dufour JF (2017 Aug 1) Other extrahepatic manifestations of hepatitis $C$ virus infection (pulmonary, idiopathic thrombocytopenic purpura, nondiabetes endocrine disorders). Clinics in Liver Disease 21(3): 607-629 
15. Hodnett PA, Naidich DP (2013) Fibrosing interstitial lung disease. A practical high-resolution computed tomography-based approach to diagnosis and management and a review of the literature. Am J Respir Crit Care Med 188(2):141-149

16. Lynch JP, editor. Interstitial pulmonary and bronchiolar disorders. Taylor \& Francis US; 2016 Apr 19.

17. Abehsera M, Valeyre D, Grenier P, Jaillet H, Battesti JP, Brauner MW (2000) Sarcoidosis with pulmonary fibrosis: CT patterns and correlation with pulmonary function. AJR Am J Roentgenol 174(6):1751-1757

18. Saleh AM, Elalfy H, Arafa MM, Abousamra N, El-Badrawy A, Mohamed MA et al (2014) Association between HCV induced mixed cryoglobulinemia and pulmonary affection: the role of TNF-alpha in the pathogenesis of pulmonary changes. Egyptian Journal of Chest Diseases and Tuberculosis 63(1):259-265

19. Hassan EA, Malek MA, Hasan AA, Ahmed AO (2015) Does hepatitis C virus enhance prevalence of idiopathic pulmonary fibrosis and affect its severity? An Egyptian study. Egyptian Journal of Bronchology 9(1):69

20. Zidan M, Daabis R, El Sayed P, Samir S (2015) Prevalence of chronic hepatitis $\mathrm{C}$ virus (HCV) infection in patients with idiopathic pulmonary fibrosis. Egyptian Journal of Chest Diseases and Tuberculosis 64(4):907-913

\section{Publisher's Note}

Springer Nature remains neutral with regard to jurisdictional claims in published maps and institutional affiliations.

\section{Submit your manuscript to a SpringerOpen ${ }^{\circ}$ journal and benefit from:}

- Convenient online submission

- Rigorous peer review

- Open access: articles freely available online

- High visibility within the field

- Retaining the copyright to your article 